\title{
Amizade e Migração Internacional: O Caso de Gregos no Espírito Santo
}

\author{
Lorena Queiroz Merizio Costa* \\ Agnaldo Garcia \\ Universidade Federal do Espírito Santo, Vitória, Brasil
}

\begin{abstract}
RESUMO
O processo de migração internacional afeta os relacionamentos de imigrantes de diferentes formas, incluindo suas amizades. A presente investigação teve por objetivo descrever as amizades de imigrantes gregos no Brasil à luz do processo de migração internacional e as relações percebidas entre essas amizades e o contexto social a partir de entrevistas com 10 imigrantes estabelecidos no Brasil havia mais de 10 anos. Os resultados indicaram que as amizades estavam associadas à percepção da receptividade do país e adaptação ao Brasil. Mudanças nas amizades anteriores à migração e o papel da comunidade grega nas amizades dos migrantes também foram investigados. Os dados são discutidos com base nas propostas de Hinde para o estudo do relacionamento interpessoal.
\end{abstract}

Palavras-chave: imigração; amizade; relações interpessoais.

\section{ABSTRACT \\ Friendship and International Migration: The Case of Greeks in Espírito Santo}

The process of international migration affects relationships of immigrants in different ways, including their friendships. The present study aimed to describe the friendships of Greek immigrants in Brazil in light of the process of international migration and the perceived relations between these friendships and social context based on interviews with 10 immigrants settled in Brazil for over 10 years. The results indicated that friendships were associated with the perception of receptivity as well as adaptation to the new country. Changes in friendships prior to migration and the role of the Greek community in friendships were also investigated. The data are discussed based on the proposals of Hinde for the study of interpersonal relationships.

Keywords: immigration; friendship; interpersonal relations.

Amizades entre pessoas de diferentes origens étnicas ou culturais representam um tema contemporâneo em função dos movimentos migratórios internacionais nas últimas décadas. Em uma revisão das amizades interétnicas, interraciais, interculturais e internacionais, Garcia e Miranda (2012) discutem a diversidade de pesquisas sobre o tema, a importância social e cultural destas amizades e a escassez de estudos sobre elas.

Segundo Fehr (1996), uma relação social de amizade é um relacionamento pessoal e voluntário que permite intimidade e ajuda e onde os amigos gostam e buscam a companhia um do outro. Com base na definição de amizade de Fehr (1996), pode-se definir amigo como uma pessoa com a qual se mantém uma relação social pessoal e voluntário, marcada pela intimidade, ajuda e companheirismo.

A literatura internacional enfatiza as relações interétnicas ou interraciais, geralmente investigando amizades entre diferentes grupos étnicos residentes em um país. Assim, uma investigação na África do Sul reuniu diferentes grupos étnicos do país para discutir amizades interculturais, tendo cada grupo destacado diferentes aspectos da amizade. Houve uma relação positiva entre o nível de poder sociocultural na África do Sul e a intensidade da identidade étnica, de modo que o grupo com maior poder sociocultural expressou 
de forma mais evidente o lado mais negativo de membros de outros grupos, assim como as preferências expressas por seu próprio grupo ou normas individuais para a amizade intercultural (Collier \& Bornman, 1999).

Kao e Joyner (2004) examinaram diferenças de atividades nas amizades interraciais e interétnicas de jovens brancos, negros, hispânicos e asiáticos nos EUA, observando ser mais provável que os melhores amigos sejam do mesmo grupo étnico e que compartilhem mais atividades, considerado um indicador de intimidade na amizade.

A relação entre amizade e preconceito tem sido abordada por vários autores. Aberson, Shoemaker e Tomolillo (2004) examinaram amizades interétnicas de euro-americanos com afro-americanos ou latinos e concluiu que euro-americanos com amigos próximos desses grupos exibiam menos preconceito que participantes sem amigos próximos no grupo alvo. Os resultados destacam a importância de contato, particularmente amizade interétnica, para melhorar atitudes intergrupo. Ainda relacionado a preconceito racial, Jacobson e Johnson (2006) relatam que 85\% dos afroamericanos que participaram de uma pesquisa aprovaram casamentos interraciais, concluindo que a quantidade de contato ou amizade entre afro-americanos e euro-americanos seria a variável crítica afetando atitudes sobre casamentos intergrupos.

Ainda relacionados à integração social, alguns estudos têm se voltado para o papel das maiorias e minorias étnicas ou raciais e sua influência sobre as relações entre membros desses grupos. Vários estudos relacionam maiorias e minorias étnicas e raciais e amizades. Fong e Isajiw (2000), por exemplo, examinaram os determinantes de padrões de amizades interétnicas entre um grupo minoritário e o grupo majoritário e amizades co-étnicas. Concluíram que a participação em atividades voltadas para o grupo étnico minoritário diminuía as chances de fazer amizades com o grupo majoritário.

Há poucas referências associando migração internacional e amizade. Kugele (2006) analisou as amizades de jovens adultos nômades indicando a relevância dos amigos na reintegração social e o significado de diferentes formas de comunicação para manter e estabelecer amizades. Haug (2003) investigou amizades interétnicas como um indicador de integração social entre jovens imigrantes italianos e turcos na Alemanha, observando que imigrantes de origem italiana faziam amizades mais frequentemente com alemães que os de origem turca. Tsai (2006) aponta que jovens imigrantes frequentemente reconstroem suas redes amizades após chegar a um novo país. Os resultados indicaram que, jovens imigrantes de Taiwan nos EUA, devido à limitação no conhecimento de inglês, mantinham-se distantes dos pares americanos, para evitar nervosismo e embaraço, aumentando a segregação. Um fator de proteção utilizado era viver perto da comunidade étnica, o que aumentava as redes de novas amizades.

Alguns estudos sobre migração internacional têm indicado a participação de amigos no processo migratório, tanto no local de origem dos migrantes quanto no local de destino, como é o caso do movimento migratório entre México e EUA (Zenteno, 2000) e de brasileiros para os EUA (Fazito \& Rios-Neto, 2008). Um grupo particular de estudos está voltado para os universitários estrangeiros em outro país. Levin, Laar e Sidanius (2003) investigaram as amizades de universitários euro-americanos, asiáticos, latinos e afroamericanos nos EUA observando que diferentes níveis de orientação para relacionar-se com outros grupos e ansiedade para relacionar-se com membros de outros grupos estavam associados à presença de amigos de fora do grupo.

Os relacionamentos entre culturas foram considerados como um importante preditor do ajustamento de estudantes estrangeiros nos EUA, por Ying (2002), que examinou a composição da rede social estudantes de pós-graduação de Taiwan nos EUA. A probabilidade de formar amizade com norte-americanos 14 meses após a chegada do pós-graduando estava positivamente associada com personalidade (i.e., extroversão), conhecimento dos EUA, atitude positiva em relação a fazer amizades com norte-americanos (associação positiva) e contexto social ambiental (disponibilidade limitada de estudantes chineses). Kudo e Simkin (2003) examinaram amizades de estudantes japoneses em uma universidade australiana, identificando como fatores para o desenvolvimento de uma amizade intercultural: (1) contato frequente, incluindo proximidade física e redes compartilhadas; (2) similaridade de características pessoais e de idade; (3) autorevelação (incluindo habilidade para falar inglês e abertura para comunicação); e, (4) receptividade em 
relação a outras nacionalidades, incluindo orientação transcultural e empatia.

Em relação a amizades entre grupos étnicos nos EUA, Constantine, Anderson, Berkel, Caldwell e Utsey (2005) observaram, como resultado do racismo, da discriminação e dos conflitos de valores culturais, que estudantes africanos têm encontrado desafios para fazer amigos e estabilizar uma rede de apoio social em universidades norte-americanas.

Algumas investigações conduzidas no Brasil sobre amizades de estrangeiros no país são relevantes para a presente investigação. Garcia e Goes (2010) investigaram amizades de universitários de Guiné-Bissau e de São Tomé e Príncipe residindo no Brasil, quanto à sua rede de amigos e as amizades mais próximas. Constatou-se que a maioria dos amigos era da mesma nacionalidade, residia na mesma cidade e foi conhecida no Brasil. A maioria das amizades foi percebida pelos próprios participantes como relevante para a adaptação ao Brasil. Os autores concluíram que os amigos são fundamentais para a adaptação social e cultural desses estudantes.

Garcia e Rangel (2011) investigaram amizades de universitários cabo-verdianos residindo e estudando no Brasil. Doze participantes citaram 109 amigos, sendo 81 cabo-verdianos, 18 brasileiros e seis angolanos. A maioria dos amigos (72) residia na mesma área metropolitana e entre os 35 amigos mais próximos, 24 eram conhecidos de Cabo Verde. Os participantes destacaram o valor da amizade e a ajuda recebida. Os episódios marcantes estavam ligados a lazer e ajuda do amigo. A maioria das amizades foi considerada como relevante para a adaptação ao Brasil.

São escassos os dados sobre a imigração grega no Brasil (Embaixada da Grécia no Brasil, 2012; Fernandes de Oliveira, 2006). Segundo dados da Embaixada da Grécia no Brasil (2012), a imigração grega no país pode ser dividida em três fases: (a) durante o Império com a vinda de algumas famílias no período de D. Pedro II; (b) entre 1914 e 1940, também com a vinda de algumas famílias; (c) após a II Guerra Mundial, entre 1951 a 1960, com o maior fluxo de gregos para o Brasil, totalizando 10.086 pessoas. De acordo com a Embaixada, de 1893 a 1979, desembarcaram no Brasil 17.018 gregos. A maior parte dos gregos e descendentes vivem em São Paulo e dedicam-se ao comércio e às profissões liberais. Ainda conforme a Embaixada, os gregos do Brasil têm mantido seus ritos e costumes reconhecendo a existência de Comunidades Helênicas em várias cidades, incluindo São Paulo, Brasília, Curitiba, Rio de Janeiro, Florianópolis, Porto Alegre e Vitória. Essas Comunidades mantêm uma Igreja Grega Ortodoxa, permitindo aos membros se reunirem e celebrarem datas cívicas e religiosas.

Segundo Fernandes de Oliveira (2006), os emigrantes gregos buscavam ocupações urbanas e, se possível, com características favoráveis a atividades marítimas, mostrando-se especialmente preocupados com a educação. Segundo a mesma autora (Fernandes de Oliveira, 2006) o Brasil começou a ser visto como uma das opções para emigrar após a II Guerra Mundial, estimando em torno de 50.000 o número de imigrantes gregos que se fixaram, constituíram família e geraram descendência em território brasileiro. A criação de entidades sociais e comunitárias e a fundação de Igrejas Ortodoxas Gregas por esses imigrantes foram relevantes para a coesão étnica e a preservação de valoras culturais trazidos da Grécia.

Fernandes de Oliveira (2006) relata ainda a tendência dos gregos no Brasil de casarem-se entre si, com os filhos recebendo nomes gregos e sendo batizados conforme rituais da Igreja Ortodoxa Grega. Conforme a autora, os imigrantes heleno-brasileiros incorporaram diversos costumes da sociedade brasileira, incluindo alimentação e hábitos quotidianos. Também informa que expressões e atitudes discriminatórias foram situações isoladas e não por ódio racial. As dificuldades de adaptação relacionaram-se principalmente ao idioma ou pela separação da pátria e dos amigos e parentes deixados para trás. O imigrante grego, em geral, não teve dificuldades em aprender a se comunicar em português, mantendo o idioma grego para se comunicar em eventos sociais entre helenobrasileiros, buscando transmitir esses conhecimentos a seus descendentes nascidos no Brasil. Ainda costumam retornar periodicamente à Grécia em viagens de passeio renovando suas informações sobre o país, dando notícias da comunidade em que vivem no Brasil, fortalecendo vínculos pessoais e os das comunidades helênicas do exterior com a pátria-mãe. O consulado grego no Espírito Santo estima haver cerca de 300 gregos no Estado, nascidos na Grécia e gregosbrasileiros, nascidos no Brasil.

A literatura sobre amizades ora investiga relações entre diferentes grupos étnicos já estabelecidos em um 
país ou amizades de estrangeiros em outro país temporariamente. Poucos investigam as amizades ao longo do processo de migração internacional. $\mathrm{O}$ presente estudo investigou amizades desde os primeiros imigrantes gregos chegando ao Espírito Santo, permitindo uma visão mais ampla de amizades de estrangeiros no país com ênfase na percepção do contexto social com vistas a compreender a participação dos amigos no processo de migração e adaptação desses imigrantes ao novo país. O objetivo desta pesquisa foi descrever as amizades de imigrantes gregos no Brasil à luz do processo de migração internacional e as relações percebidas entre essas amizades e o contexto social.

\section{MÉTODO}

O presente trabalho apresenta os resultados de uma pesquisa de campo qualitativa, com características descritivo-exploratórias, tendo como plano o estudo retrospectivo de casos múltiplos.

\section{Participantes}

Foram entrevistados dez imigrantes gregos que vieram para o Brasil com dez anos de idade ou mais e morando no país há mais de dez anos. Os seguintes critérios de inclusão foram utilizados: (a) o participante deveria ter nascido na Grécia; (b) deveria ter migrado para o Brasil com pelo menos dez anos de idade, de modo que tivesse vivido ao menos parte da infância no país de origem e que tivesse vivido as primeiras experiências de amizade na Grécia; (c) que estivesse morando no Brasil há mais de dez anos, para que pudesse apresentar um período mínimo em comum para experiências com amigos no Brasil.

Os participantes foram selecionados pela facilidade de acesso e por estarem de acordo com os critérios de inclusão. Os dados referentes aos participantes estão indicados no quadro a seguir:

Quadro 1

Identificação dos participantes da pesquisa, selecionados de acordo com os critérios preestabelecidos

\begin{tabular}{|l|l|l|l|l|c|c|}
\hline Participante & $\begin{array}{c}\text { Local de } \\
\text { Origem }\end{array}$ & $\begin{array}{c}\text { Idade que } \\
\text { chegou ao } \\
\text { Brasil }\end{array}$ & $\begin{array}{c}\text { Situação } \\
\text { civil }\end{array}$ & Filhos & $\begin{array}{c}\text { Idade na } \\
\text { época da } \\
\text { entrevista }\end{array}$ & $\begin{array}{c}\text { Tempo de } \\
\text { permanência } \\
\text { no Brasil }\end{array}$ \\
\hline Ábaris & Atenas & 11 anos & Casado & Sim & 52 anos & 41 anos \\
\hline Anteros & Patras & 19 anos & Casado & Sim & 64 anos & 45 anos \\
\hline Athamas & Corintos & 25 anos & Casado & Sim & 56 anos & 31 anos \\
\hline Eurídice & Atenas & 28 anos & Casada & Sim & 39 anos & 11 anos \\
\hline Ícaro & Andros & 21 anos & Casado & Sim & 73 anos & 52 anos \\
\hline Kairos & Atenas & 29 anos & Casado & Sim & 75 anos & 46 anos \\
\hline Minos & Lacônia & 15 anos & Casado & Sim & 68 anos & 53 anos \\
\hline Stafilos & Esparta & 11 anos & Casado & Sim & 63 anos & 52 anos \\
\hline Tácita & Esparta & 15 anos & Casada & Sim & 68 anos & 53 anos \\
\hline Vanília & Chalandri & 22 anos & Casada & Sim & 70 anos & 48 anos \\
\hline
\end{tabular}

\section{Procedimentos}

Como estudo retrospectivo de relacionamentos considerou-se relevante incluir narrativas como uma forma de ter acesso aos dados, visto que "através da narrativa, as pessoas lembram o que aconteceu, colocam a experiência em uma sequência, encontram possíveis explicações [...], e jogam com a cadeia de acontecimentos que constroem a vida individual e social"
(Jovchelovitch \& Bauer, 2008, p. 91). Portanto, narrativas são formas de avistar e compreender o mundo, sendo consequências da inter-relação entre os fatos pessoais e as vidas que compõem a história contada no espaço e no tempo. Contudo, conforme Flick (2009, p. 178), "nem tudo pode constituir um tópico em uma apresentação narrativa, de modo que, às vezes, são necessárias formas complementares para 
abordar as experiências que se quer investigar". Por outro lado, a natureza conceitual da área de estudos sobre relações interpessoais, conforme Hinde (1997), indicou a necessidade de incluir-se conceitos sobre relacionamentos, optando-se por uma forma de entrevista que permitisse integrar aspectos narrativos e conceituais, no caso, a entrevista episódica.

De acordo com Flick (2009), a entrevista episódica parte do pressuposto de que "as experiências de um sujeito sobre um determinado domínio sejam armazenadas e lembradas nas formas de conhecimento narrativo-episódico e semântico" (p. 172). Segundo o autor, essas duas formas de conhecimento estão relacionadas, de modo que "o conhecimento episódico possui uma organização que se aproxima mais das experiências, estando associada a situações e a circunstâncias concretas". Por outro lado, "o conhecimento semântico baseia-se em suposições e em relações abstraídas destas e generalizadas" (Flick, 2009, p. 172).

Através da entrevista episódica, pode-se então ter acesso ao relacionamento como uma experiência histórica e narrativa e também ao pensamento conceitual sobre essas relações (Flick, p. 172). Quanto ao plano básico como pesquisa qualitativa, trata-se de um estudo retrospectivo de casos múltiplos. Conforme Flick (2009, p. 135), "o objetivo dos estudos de caso é a descrição exata ou reconstrução de um caso". Em relação aos estudos retrospectivos estes "funcionam com uma série de análises de caso de uma forma comparativa, tipologizante e contrastante" (Flick, 2009, p. 136).

As informações obtidas por meio de entrevista episódica foram objeto de análise temática. Para a realização da análise temática foi utilizado o procedimento recomendado por Jovchelovitch e Bauer (2008) de redução gradual do texto qualitativo, buscando-se a generalização e condensação de sentido. Partiu-se, então, para a codificação e categorização do texto, individualmente, para cada entrevista, procurando-se, através de comparações e revisões chegar-se a um sistema único de classificação e organização do material, conforme proposto por Jovchelovitch e Bauer (2008).

As revisões e comparações permitiram uma aproximação entre as estruturas presentes no material dos entrevistados com as estruturas teóricas presentes na literatura e que guiaram a organização de investigação, de modo que "o produto final constitui uma interpretação das entrevistas, juntando estruturas de relevância dos informantes com as do entrevistador" (Jovchelovitch \& Bauer, 2008, p. 107).

O procedimento está de acordo com o referencial teórico adotado, tendo Hinde (1997) proposto a descrição e classificação dos relacionamentos, a especificação dos princípios envolvidos em sua dinâmica e o reconhecimento das limitações da aplicabilidade desses princípios. A obra de Hinde (1997) serve como referencial teórico mais amplo em relação a uma opção metodológica, que parte da descrição e classificação dos relacionamentos seguindo para a especificação dos princípios envolvidos em sua dinâmica. Como o autor não investigou a amizade especificamente, outros autores são utilizados para a discussão. As entrevistas foram realizadas individualmente, sendo gravadas e posteriormente transcritas. Os participantes assinaram termo de consentimento e foram entrevistados com base em um roteiro semiestruturado que buscou investigar o papel dos amigos no processo de migração e estabelecimento no Espírito Santo. Os dados foram analisados qualitativamente e organizados de acordo com similaridades entre os temas discutidos. Para manter em sigilo a identidade dos participantes, nomes fictícios são utilizados.

O conceito ou definição de amigo não foi apresentado de forma prévia aos entrevistados, em função da pesquisa buscar compreender como os próprios entrevistados conceituavam o amigo e a amizade. Esta opção foi feita para possibilitar que se permitisse ver possíveis diferenças culturais no conceito de amizade, permitindo assim uma compreensão mais fiel para os entrevistados de sua visão sobre amizade de acordo com suas tradições culturais.

Deve-se apontar que as entrevistas, como memórias, são construções presentes sobre o passado, relacionadas a sistemas simbólicos ressignificados. Para tanto, trabalhou-se com memórias e também com a realidade. Entende-se que cada um constrói sua história no decorrer da vida a partir de sua realidade particular e específica, de seu cotidiano corriqueiro e sempre relevante (Bosi, 2004). Com as memórias e com o dia-a-dia foi possível construir a relação de cada um com sua concepção de amizade, uma vez que esta 
mesma a amizade tem o poder de transformar em vida aquilo que não passa de mera realidade.

\section{RESULTADOS}

Diversos aspectos surgiram nas entrevistas com imigrantes gregos no Espírito Santo sobre imigração e amizades. Após análise, seis dimensões relacionando amizade e contexto social foram propostas: receptividade e amizade, adaptação e amizade, amizades anteriores, a Comunidade Helênica e relacionamentos, e a escolha de amigos.

\section{Receptividade e Amizade}

Um tema recorrente nas entrevistas diz respeito ao acolhimento ou receptividade do povo brasileiro em relação aos imigrantes. A receptividade é um conceito que indica a abertura e disponibilidade do povo local em relação a receber pessoas de diferentes origens e estabelecer laços de amizade com pessoas de outros países.

Eurídice declara sempre ter sido muito bem tratada no país e sente-se grata pelo acolhimento recebido e que as características do povo contribuíram imensamente para que formasse laços de amizades e se adaptasse à cultura local. Crê que os brasileiros lidam bem com qualquer nacionalidade. Por suas amizades no Brasil sente-se à vontade no país e não anseia em retornar à Grécia a não ser nas férias. Para ela,

[...] foi fácil aqui no Brasil, porque fui muito bem recebida desde o início, então fiquei mais à vontade. Hoje tenho mais amigos brasileiros que gregos, e vejo diferença em como me relaciono. Brasileiro não liga para sangue. É amigo e pronto.

Vanília também se sentiu acolhida ao chegar ao país. Suas primeiras amizades foram com amigos dos familiares de seu marido e com brasileiros que os recebiam sem conhecê-los. Anteros afirma que "fomos bem recebidos, fomos bem recebidos", demonstrando gratidão pelo companheirismo encontrado nas amizades com brasileiros, e a importância de tais relações para sua compreensão dos costumes e comportamentos aqui encontrados. Por ser um dos primeiros gregos no estado, não contava com a solidariedade de conterrâneos, o que fez com que intensificasse e valorizasse ainda mais suas amizades com brasileiros, que o orientavam também na questão profissional. As primeiras pessoas que conheceu ao chegar ao Espírito Santo tornaram-se seus amigos e essas amizades perduram até os dias de hoje, ressaltando o papel de cada um deles para seu estabelecimento e continuidade no país. Assim, "Tenho amigos daquele tempo. Tem um amigo que é a primeira pessoa que eu conheci... não sei nem quantos anos, mas muitos anos... que a gente se encontra; é meu amigo ainda. E a primeira pessoa que eu conheci foi ele". Diz ainda que seus amigos também criaram vínculos com sua esposa e seus filhos, tornando-se amigos da família.

De modo análogo, a construção de amizades com brasileiros no decorrer do tempo trouxe a Athamas maior tranquilidade e conforto no país escolhido para viver. Quando estava estabelecendo-se profissionalmente, enfrentou uma situação financeira difícil e foi auxiliado por um amigo brasileiro. Esse acontecimento despertou em Athamas gratidão pelo povo brasileiro. Emocionado, declara que "Eu... sou muito grato ao Brasil". Emocionado, tenta verbalizar o sentimento construído pelo país que o acolheu, declarando que sente o "[...] calor dos amigos" aqui. Assim, declara ter

[...] grandes amigos brasileiros, que posso dizer hoje que tenho mais amigos brasileiros que com próprios gregos, que tive a dificuldade. Então, eu só tenho que agradecer, muito obrigado, porque, num momento dificil, o meu apoio, tive mais apoio dos amigos brasileiros que dos amigos gregos.

Eurídice considera, dentre outros fatores, que características como receptividade e acolhimento dos brasileiros contribuíram para optar em residir definitivamente aqui. Os laços criados com brasileiros influenciaram sua decisão de permanecer no Brasil e adotá-lo como sua nação. A influência das amizades brasileiras em sua vida é exemplificada da seguinte maneira: "Por isso que eu digo que é muito fácil e muito perigoso pro grego perder as suas raízes aqui, por conta disso. Porque o Brasil acolhe muito bem. $O$ brasileiro acolhe muito bem". No que se refere às amizades construídas com brasileiros, destaca a facilidade com que aconteceram e a sinceridade sentida em cada uma delas desde seus primeiros dias.

Ícaro sempre se sentiu acolhido e bem recebido pelos brasileiros. Segundo ele, "Desde que cheguei, tenho amigos aqui. Me receberam, ensinaram viver 
no Brasil. Eu gostei. [...] Por isso foi fácil me adaptar". Ícaro aventurou-se mundo afora tendo encontrou amizades sinceras aqui, a ponto de optar pelo Brasil como seu país de residência.

As amizades também fortaleceram a decisão de Kairos em residir no Brasil. Ele afirma que não houve dificuldade para se estabelecer no Brasil, visto que foi bem acolhido desde seus anos iniciais. Considera que "[...] não tinha grego diferente de brasileiro. Brasileiro me deu oportunidade aqui. Amigo meu até hoje". Ser considerado pelos brasileiros como parceiro e não como invasor trouxe tranquilidade para Kairos. Em seu ofício, visa transmitir aos seus funcionários, acolhimento semelhante ao recebido dos brasileiros. Reconhece que as amizades construídas nessa época - e que ainda perduram - fizeram com que não se sentisse sozinho e desamparado. Com o passar do tempo, aproximou-se de outros gregos que chegaram na mesma época, ampliando suas amizades com brasileiros e patrícios.

Stafilos afirma que o povo brasileiro é um dos mais hospitaleiros que existe, uma vez que recebe muito não apenas o grego, mas qualquer estrangeiro. Alguns de seus amigos são de outra origem, " $E$... principalmente de origem árabe. Muitas. Aqui você sabe que o Brasil também... o Espírito Santo... colônia libanesa, né, sírio-libanesa... árabes de qualquer maneira", apesar de não estabelecer com frequência contato com eles. Stafilos destaca que sempre foi privilegiado por ser estrangeiro, visto que estabeleceu diversas amizades que se iniciaram exatamente pela curiosidade que despertava nos demais indivíduos. Ele afirma que "sempre me dei muito bem com gente, como se diz, tenho amizades duradouras, muito boas, muito boas. Não tive dificuldade nenhuma". Para ele, a cultura brasileira costumava privilegiar pessoas e artigos importados em detrimento de suas próprias construções.

Para Ábaris, amigo não é somente uma pessoa agradável e interessante, mas sim alguém capaz de causar diferença no cotidiano de outrem. Ele encontrou acolhimento e companhia no povo brasileiro, tecendo amizades intensas e duradouras. A receptividade social ou relacional (possibilidade de formar amizades) está relacionada com a adoção do país como lugar para viver por parte dos estrangeiros, relacionase com as amizades estabelecidas e com a adaptação ao novo país.
Enquanto a receptividade indica o potencial de aceitação de um elemento estrangeiro, a adoção representa a opção do outro pelo Brasil. Em vários momentos, os participantes indicaram sua opção em viver no Brasil. A história de Ícaro com o Brasil demonstra a participação de amigos em adotar o Brasil como lar. Ele chegou ao Brasil nos anos de ditadura militar, especificamente em 1964. Na época do Ato Institucional número 5 (AI-5), em 1968, foi questionado por alguns amigos brasileiros, que se preocupavam com sua segurança, se não deveria deixar o país por um tempo, até que a situação política se restabelecesse mais favoravelmente ao povo. No entanto, Ícaro, declarou: "[...] ir embora pra quê, se os meus amigos estão todos aqui, se minha filha é brasileira?". Desse modo, fixou residência no Brasil e tomou os amigos como familiares. Declara que preserva suas amizades nos 'moldes brasileiros', expressando sua opinião aos amigos e fazendo o possível para não os deixar tomar atitudes indesejáveis em seu dia-a-dia, afinal, "amigo faz isso". O acolhimento desde quando chegou ao Brasil afetou sua permanência no país.

\section{Adaptação e Amizade}

Neste trabalho, a adaptação é considerada um processo pelo qual o imigrante promove uma série de mudanças para aproximar-se das práticas de outro país, permitindo viver de acordo com padrões da nova terra. Todos os participantes admitem que as amizades com brasileiros contribuíram para que se adaptassem ao país, promovendo maior integração social e cultural ao Brasil.

Muito do que Anteros aprendeu sobre o Brasil ocorreu via amigos, que promoveram a integração do participante aos costumes brasileiros, de maneira que este não se sentiu deslocado em momento algum, apesar de inúmeras novidades, afirmando que "Fiz amigos, me distraí, fui aprendendo sem nem ver".

Stafilos afirma que "eu me adaptei muito bem, nunca me senti rejeitado, e por ser grego sempre fui muito, assim... privilegiado. Seja no colégio, seja na amizade...". Stafilos frequentou escolas brasileiras por alguns anos em virtude de ter vindo para cá em idade escolar, e acredita que o fato de ser grego facilitou as amizades, uma vez que era considerado diferente - no sentido positivo do termo - dos demais amigos da escola. 
Em relação à importância das amizades para sua adaptação ao Brasil, Minos diz que "[...] esse carinho é pra nós algo muito importante". Como morou apenas com seu pai durante um período, os amigos da escola fizeram a mediação entre ele e seu entorno: era um adolescente estrangeiro, que não dominava a linguagem, não conhecia os costumes brasileiros e não estava com os familiares por perto. Embora preserve intensamente as tradições gregas, os amigos do Brasil facilitaram sua compreensão dessa nova fase de sua vida e lhe ensinaram a ser feliz longe de sua terra. Para Minos, manter amizades com patrícios foi fundamental para que se adaptasse ao Brasil. Seus amigos brasileiros contribuíram imensamente para que se organizasse e compreendesse o ritmo de funcionamento da sociedade brasileira; seus amigos gregos o confortaram afetivamente, em detrimento da saudade que sentia de sua terra de origem. Ter amigos facilitou a adaptação ao Brasil de todos os participantes, independentemente da idade em que aportaram no Brasil.

\section{Amizades Anteriores}

As amizades anteriores ou se mantiveram ou declinaram. Eurídice destaca alguns amigos de infância com os quais mantêm contato e encontra, às vezes, quando vai à Grécia. Trata-se de vínculos criados enquanto morava lá. Reconhece ter sentido falta das amizades de lá que, por muitos meses, permearam seus pensamentos diante do porto de Vitória, onde aguardava que algum amigo pudesse aportar a qualquer hora. Conforme criava vínculos com brasileiros e, posteriormente com gregos, a saudade diminuía.

[...] tem um cais, que vem sempre navio, então eu chegava a sonhar todo dia, até pelo menos eu casar. Aqueles navios que paravam ali, nas lojas que a gente tinha, chegavam gregos, da marinha mercante, como é até hoje. Falei mais para as quatro que eram amigas, porque outras que tavam ali eu nem conhecia: "se aparecessem uma das quatro cada com algum senhor do navio, ia aparecer na minha frente, e era...", já tinha se tornando não um sonho só, uma esperança [riso quieto], e nunca aconteceu.

Tácita tem três grandes amigas na Grécia com as quais se comunica por telefone. Quando se encontram, conversam por muitas horas, para que se atualizem dos acontecimentos. Essas amizades foram edificadas nos anos em que Tacita teve que morar na Grécia em decorrência do trabalho de seu esposo. As amizades escolares não foram mantidas, já que Tacita nunca mais as encontrou, mas as considera como amigas.

Stafilos experimentou as amizades gregas por pouco tempo, vindo para o Brasil na adolescência. Apesar de ter ido poucas vezes à Grécia nos últimos anos, Stafilos usualmente procura pelos amigos quando está lá, da escola e primos considerados amigos. Afirma que as amizades mantidas lá não estão esquecidas, mas apenas adormecidas, acreditando que o tempo não fará diferença quando se encontrarem.

Em seus primeiros anos de Brasil, Tacita foi privada de interações por seu pai, sentindo grande falta das amizades das vizinhas, desejando imensamente vê-las desembarcando em algum navio. Posteriormente, conheceu brasileiros e gregos que se tornaram seus amigos e facilitaram sua adaptação ao país.

Outros se afastaram dos amigos. Kairos desiludiuse com como seus antigos amigos pela forma como se portaram com seu regresso ao país e compreendeu que seus costumes e os dos conterrâneos não eram mais os mesmos:

Morava fora da Grécia há quinze anos... Bom, fui. Cheguei no aeroporto; tava me esperando o meu irmão e a minha irmã [...] Esperava meus amigos gregos, esperava eles lá. Um dia pensei: amigos que imaginava que ia encontrar lá, quinze anos depois, $e$ nada. Foi a mesma coisa que chegar num país estranho. Quinze anos depois, pela primeira vez... ninguém.

Vanília não mantém contato com amigos deixados na Grécia e não demonstra saudade dos mesmos. Eurídice declara sentir-se à vontade para conversar com amigos antigos, deixados na Grécia, embora só o faça raramente. Athamas não manteve amigos em seu país de origem.

\section{A Comunidade Helênica e Relacionamentos}

A Comunidade Helênica foi criada como instituição em 1992, com o objetivo principal de manter a cultura, costumes e tradições helênicas no exterior, com aulas de música, do idioma e de danças típicas entre outras, oferecidas ao público. Além disso, todos podem participar das comemorações gregas ao longo do ano. Grata pelo acolhimento, Tácita, com o intuito 
de apresentar sua cultura para seus amigos brasileiros, queria

Juntar nosso povo pra mostrar pra amigos brasileiros o que a gente fazia... A gente levava amigos brasileiros pra nossas reuniões. Brasileiro sempre foi nossos amigos, então a gente queria que ficasse com a gente também. [...] Até hoje meu marido tem amigos dos primeiros dias dele aqui no Brasil.

Anteros se orgulha das visitas que os amigos brasileiros fazem à Comunidade Helênica. A existência da Comunidade facilita a manutenção da rede social entre os gregos do estado. Athamas afirma que, nos primeiros anos da Comunidade, o grupo de amigos em comum era maior. Com o decorrer dos anos, e com o crescimento profissional e estabilização financeira de alguns membros, os núcleos de amizade foram se refazendo a partir da situação social de cada um.

A Comunidade Helênica, para Anteros, promove encontros entre amigos, mantendo as amizades entre os envolvidos. Tacita reconhece que a Comunidade favorece o entrosamento entre os gregos e faz com que todos se considerem 'amigos' uns dos outros, embora não exista de fato, tal vínculo. As amizades gregas de Stafilos começaram e são mantidas através da comunidade e seu contato com esses amigos restringe-se aos encontros na Colônia.

Para Tácita, a Comunidade favoreceu amizades com gregos no Brasil, promovendo o contato entre os compatriotas. Atualmente Vanília comunica-se com seus amigos gregos no Brasil pela Comunidade. Anteros afirmou ser amigo de todos na Comunidade. Encontrar compatriotas favorecia a redução da saudade da pátria e amizades com gregos tornaram-se necessárias para manter a tradição no país. Minos acredita que a amizade mantém a comunidade grega unida, pois "isso não deixa perder a nossa cara, nosso contato, nossos costumes". Logo, a Comunidade surge como facilitadora dos encontros entre os amigos.

A comunidade grega funciona como rede, e os contatos passam de membro a membro. $\mathrm{Na}$ opinião de Minos, o critério mais importante para selecionar amigos é que estes devem ser apresentados por uma pessoa conhecida e amiga, a fim de que ele se sinta suficientemente seguro para comunicar-se e envolverse com eles. Afirma tentar tratá-los “[...] como sendo amigo meu de muitos anos".
A existência de uma comunidade grega em Vitória não significa que todos os gregos vivam em plena harmonia entre si. No que se refere às suas primeiras amizades gregas em terras brasileiras, Kairos não se sentiu à vontade com esses conterrâneos. Quando declarou que estava decidido a ficar no Brasil, estes não o acolheram; ao contrário, manifestaram incômodo pela sua presença, pois o reconheceram como ameaça. Com o decorrer dos anos, Ábaris tornou-se apenas visitante do espaço grego em Vitória, mantendo relações cordiais. No que tange à amizade, destaca a diferença que considera entre amigos e conhecidos: “[...] hoje se você me disser assim, hoje você tem algum amigo grego?, eu vou te dizer assim, eu tenho conhecidos, certo?! [...] são conhecidos. Eu tenho entre meus conhecidos, entre pessoas que me relaciono, carinho", não os inserindo em seu rol de amigos.

Athamas mostra saudosismo ao relatar as amizades entre gregos no Espírito Santo em virtude de identificar, nos últimos anos, consideráveis alterações no modo como as redes de amizade se configuraram, em sua visão. Pessoas que obtiveram conquistas semelhantes se aproximaram mais do que outras. É o que denomina de 'proximidade econômica' gerando maiores possibilidades de atividades em comum, favorecendo redes de amizade. Para ele, questões comerciais contribuíram para modificações nas relações entre alguns de seus conterrâneos.

Para Eurídice, poucas foram as amizades estabelecidas com gregos residentes no Espírito Santo. Afirma que gosta dos membros da Colônia, embora não os considere amigos de fato. É evidente a não proximidade de Ábaris com seus patrícios. Os gregos, de modo geral, convivem com seus patrícios, embora não exista amizade entre todos.

\section{A Escolha de Amigos}

Diante da presença de brasileiros e gregos, não há distinção entre as nacionalidades para se fazer amigos. Tácita não faz distinção entre nacionalidades, assegurando que amizade não depende do país de nascimento, mas das afinidades desenvolvidas entre as pessoas, classificando suas amizades gregas e brasileiras como excelentes, respeitando as especificidades de cada uma. Para Vanília não faz diferença ser amiga de brasileiro, grego ou de qualquer outra nacionalidade. Ícaro também não diferencia amigos, não separando 
suas amizades com conterrâneos ou demais nacionalidades. Para Tácita, o que importa na relação é sentirse bem e segura na presença da outra pessoa, independentemente da nacionalidade. Ícaro não aponta diferença na maneira com a qual se relaciona com amigos gregos e brasileiros, apesar de identificar peculiaridades em cada cultura. Possui mais amigos brasileiros por estar no Brasil, não fazendo distinção entre os amigos e suas culturas. Sabe que o modo de se portar é variado com gregos e com brasileiros. Entre os gregos "[...] sou Ícaro; pra brasileiros, sou grego".

Stafilos, Ábaris, Athamas, Ícaro e Vanília possuem mais amigos brasileiros do que gregos. Stafilos diz: "não privilegio os gregos. Então, amigos meus de verdade são muito mais brasileiros". Os maiores amigos de Vanília são das duas nacionalidades, atualmente, possuindo mais amigos brasileiros que gregos, em virtude das amizades dos filhos, que são nascidos e criados aqui. Anteros fazia questão de unir amigos brasileiros aos gregos. Mesmo com novas famílias gregas instalando-se no estado, não se descuidou das amizades brasileiras, não privilegiando as relações com os conterrâneos. Ele destaca que o aspecto cultural fez com que se aproximasse dos patrícios. Anteros sempre buscou incentivar novas amizades entre seus amigos brasileiros e gregos.

Vanília compartilhava as mesmas atividades realizadas com amigos gregos e brasileiros. Muitas vezes unia as duas nacionalidades para um piquenique, para uma celebração grega ou para passar o dia na praia. Afirma que seus melhores amigos são os gregos daqui e os brasileiros. Não construiu amizades com gregos simplesmente por ser compatriota, de modo que "Era grego também. Não era amigo, mas era grego". Afirma que pode haver auxílio entre gregos, mas amizade deve ser construída independentemente da nacionalidade. Por esse motivo, declara que não fez diferenciação entre brasileiros e gregos.

\section{DISCUSSÃO}

Enquanto alguns estudos sobre migração internacional têm indicado a participação de amigos no processo migratório sem investigar como as amizades se desenvolvem após a migração (Fazito \& Rios-Neto, 2008; Zenteno, 2000), o presente estudo procurou investigar as amizades ao longo do processo de migra- ção e estabelecimento no país. Os seguintes aspectos se destacaram nos relatos sobre migração e amizade: a relação entre amizade e percepção da receptividade do país, amizades como elementos para uma decisão para adotar o país como local para viver, a manutenção ou afastamento de velhos amigos, a relevância das amizades para a adaptação ao novo país, organização de uma comunidade grega no Estado e seus efeitos sobre as amizades e as escolhas da amizade.

As entrevistas se referem diversas vezes à receptividade do Brasil e dos brasileiros, sendo raros e ambíguos os episódios de rejeição, preconceito ou discriminação. Várias referências à receptividade estão associadas à presença de amizades, indicando a abertura e disponibilidade do povo local em receber ou acolher pessoas de diferentes origens e estabelecer laços de amizade. A receptividade indica relações entre o indivíduo e seu contexto social, favorecendo o estabelecimento de relações de amizade.

Alguns estudos voltados para universitários estrangeiros em outro país têm proposto aspectos próximos ao que foi denominado de receptividade nesta pesquisa, como orientação para relacionar-se com outros grupos (Levin et al., 2003), atitude positiva em relação a fazer amizades com outras nacionalidades (Ying, 2002) e receptividade em relação a outras nacionalidades, incluindo orientação transcultural e empatia (Kudo \& Simkin, 2003). Nos três casos, a receptividade ou orientação transcultural é atribuída ao estudante estrangeiro, enquanto nesta pesquisa, os participantes destacam a receptividade por parte dos brasileiros. Por sua vez, as amizades parecem favorecer a adoção do país como lugar para se viver definitivamente.

Ao contrário do que tem sido observado com estudantes universitários estrangeiros (Andrade \& Teixeira, 2009; Constantine et al., 2005; Garcia \& Goes, 2010; Garcia \& Rangel, 2011), os participantes não relataram desafios ou dificuldades para fazer amigos ou preferência por amigos da mesma nacionalidade. Assim como observado por Aberson et al. (2004), os dados sugerem que amizades com brasileiros melhoram as atitudes intergrupo, por parte dos imigrantes. De modo diverso dos jovens imigrantes de Taiwan nos EUA (Tsai, 2006), não houve segregação percebida devido à limitação no conhecimento de português. 
Adaptação, no presente artigo, se refere ao processo de ajustamento às condições ambientais existentes (Castro, 2003). Ward, Bochner e Furman (2001) reconhecem duas formas de adaptação intercultural: a adaptação sociocultural, que indica a habilidade de interagir com uma cultura diferente; e a adaptação psicológica, que promove a sensação de bem-estar do indivíduo e sua avaliação positiva de situações e a satisfação geral com a vida. As amizades parecem afetar ambas as formas em relação aos gregos no Brasil. Ter amigos facilitou a adaptação no Brasil de todos, independentemente da idade em que aportaram no Brasil. Segundo a classificação proposta por Berry (2001), o processo de aculturação observado seria o de integração, quando o migrante preserva a herança cultural e ainda adquire algumas características da cultura hospedeira. Os participantes indicaram amizades com brasileiros como fundamentais para que se adaptassem e se sentissem satisfeitos com a migração realizada, promovendo maior integração social e cultural ao Brasil, o que também foi observado em outros estudos (Garcia \& Goes, 2010; Garcia \& Rangel, 2011). Como observado por Kugele (2006) em relação a grupos nômades, amigos se mostram relevantes para a integração social. Também de acordo com Haug (2003), pode-se considerar que as amizades com brasileiros podem ser vistas como um indicador de integração social no Brasil.

Com base na definição de amizade de Fehr (1996), pode-se definir amigo como uma pessoa com a qual se mantém uma relação social pessoal e voluntário, marcada pela intimidade, ajuda e companheirismo. Ao falar sobre amigos, os participantes incluíram entre os amigos aquelas pessoas com as quais mantiveram alguma forma de contato positivo, mesmo que não houvesse indicação de uma maior intimidade.

Mesmo após a migração, os gregos mantêm amizades no país de origem. As amizades com outros gregos no Brasil também estão presentes, mas não de forma exclusiva. As preferências expressas por seu próprio grupo, observada em outros ambientes multiculturais não foi observada neste estudo (Collier \& Bornman, 1999). Também não revelam preferência por atividades compartilhadas com o mesmo grupo ou indicam o melhor amigo como pertencendo a esse grupo (Kao \& Joyner, 2004).
Os participantes não citaram qualquer forma de coerção familiar ou grupal para sua integração à cultura e à sociedade local, podendo ser considerada como uma opção individual. Neste caso, deve-se lembrar que os mesmos permaneceram ligados a outras pessoas de seu país de origem, incluindo seus familiares.

A formação de uma comunidade, segundo Fernandes de Oliveira (2006), é relevante para a coesão étnica e a preservação de valores culturais gregos. A formação de uma comunidade grega afetou as amizades de várias formas, contudo sem restringi-las ao grupo. De modo geral, as amizades foram importantes para a adaptação e permanência dos imigrantes gregos no Brasil e não foram relatadas dificuldades em sua formação e desenvolvimento, o que não tem sido observado no caso de outros estrangeiros no país, como estudantes universitários. Os elos entre o contexto social e os relacionamentos (amizades) é um dos aspectos propostos por Hinde (1997) sobre o tema, além da relevância da utilização de descrição e sistematização dos dados.

A presente investigação permitiu acompanhar as amizades de imigrantes gregos desde sua chegada ao Brasil, indicando a relevância destas para a integração social e cultural dos participantes. O trabalho, contudo, limitou-se à investigação da imigração grega no Estado do Espírito Santo, sendo necessários, no caso brasileiro, outras investigações sobre amizade em outros grupos de imigrantes. Também são necessárias mais investigações sobre a presença de estrangeiros no país e suas amizades como indicadores de integração social, uma vez que os dados indicam situações diferentes, como é o caso das amizades de estudantes universitários estrangeiros no Brasil. Outras pesquisas ainda poderiam investigar algumas formas pelas quais os participantes se referiram aos relacionamentos interpessoais, como a importância das relações de parentesco (sangue) ou relações com o país de origem (raízes).

Ao indicar a relevância das amizades para sua integração social e cultural, os participantes apontam para a amizade como um relacionamento que permitiu sua participação em um contexto social mais amplo, não apenas mantendo vínculos com outros gregos no Brasil, mas criando laços com brasileiros também.

Pode-se concluir que, a partir dos relatos apresentados, as amizades foram percebidas como relevantes para o contexto social no qual os imigrantes passaram 
a viver, permitindo uma melhor inserção em uma nova sociedade e cultura, além de manter os laços e a tradição cultural do país de origem.

\section{REFERÊNCIAS}

Aberson, C. L., Shoemaker, C., \& Tomolillo, C. (2004). Implicit Bias and Contact: The Role of Interethnic Friendships. Journal of Social Psychology, 144, 335347.

Andrade, A. M. J. de, \& Teixeira, M. A. P. (2009). Adaptação à universidade de estudantes internacionais: Um estudo com alunos de um programa de convênio. Revista Brasileira de Orientação Profissional, 10, 33-44.

Berry, J. W. (2001). A psychology of immigration. Journal of Social Issues, 57, 615-631.

Bosi, E. (2004). O tempo vivo da memória: ensaios de psicologia social. São Paulo: Ateliê Editorial.

Castro, V. S. (2003). Acculturation and psychological adaptation. Westport: Greenwood Press.

Collier, M. J., \& Bornman, E. (1999). Core symbols in South African intercultural friendships. International Journal of Intercultural Relations, 23, 133-156.

Constantine, M. G., Anderson, G. M., Berkel, L. A., Caldwell, L. D., \& Utsey, S. O. (2005). Examining the Cultural Adjustment Experiences of African International College Students: A Qualitative Analysis. Journal of Counseling Psychology, 52, 57-66.

Embaixada da Grécia no Brasil (2012). A Imigração Grega no Brasil. Retirado em 5 de junho de 2012, de http://www.emb-grecia.org.br/pt/greeks/historia.htm

Fazito, D., \& Rios-Neto, E. L. G. (2008). Emigração internacional de brasileiros para os Estados Unidos: as redes sociais e o papel de intermediação nos deslocamentos exercido pelas agências de turismo. Revista Brasileira de Estudos Populacionais, 25, 305-323.

Fehr, B. (1996). Friendship processes. Thousand Oaks, CA: Sage.

Fernandes de Oliveira, M. G. (2006). Historiografia do processo imigratório brasileiro: um olhar sobre comunidades helênicas no Brasil. Estúdios Humanísticos. Filología, 28, 263-275.

Flick, U. (2009). Introdução à Pesquisa Qualitativa ( $3^{\mathrm{a}}$ ed.) (J. E. Costa, Trad.). Porto Alegre: Artmed.

Fong, E., \& Isajiw, W. W. (2000). Determinants of friendship choices in multiethnic society. Sociological Forum, $15,249-271$.

Garcia, A., \& Goes, D. C. (2010). Amizades de Estudantes Africanos residindo no Brasil. Psicologia: Teoria e Prática, 12, 138-153.

Garcia, A., \& Miranda, R. F. (2012). Amizades interculturais, interétnicas, interraciais e internacionais. Em: L. K. de Souza \& C. S. Hutz (Orgs.). Amizade em contexto: desenvolvimento e cultura (pp. 229-260). São Paulo: Casa do Psicólogo.

Garcia, A., \& Rangel, P. M. V. (2011). Amizades de universitários cabo-verdianos no Brasil. Psicologia Argumento, 29, 201-208.

Haug, S. (2003). Interethnische Freundschaftsbeziehungen und Soziale Integration: Unterschiede in der Ausstattung mit sozialem Kapital bei jungen Deutschen und Immigranten. Kölner Zeitschrift für Soziologie und Sozialpsychologie, 55, 716-736.

Hinde, R. A. (1997). Relationships: a dialectical perspecti$v e$. Hove: Psychology Press.

Jacobson, C. K., \& Johnson, B. R. (2006). Interracial friendship and African American attitudes about interracial marriage. Journal of Black Studies, 36, 570-584.

Jovchelovitch, S., \& Bauer, M. W. (2008). Entrevista narrativa. Em: M. W. Bauer \& G. Gaskell (Orgs.). Pesquisa qualitativa com texto, imagem e som: um manual prático (pp. 90-113) (7ª ed.) (P. A. Guareschi, Trad.). Petrópolis: Vozes.

Kao, G., \& Joyner, K. (2004). Do Race and Ethnicity Matter among Friends? Activities among Interracial, Interethnic, and Intraethnic Adolescent Friends. Sociological Quarterly, 45, 557-573.

Kudo, K., \& Simkin, K. A. (2003). Intercultural Friendship Formation: the case of Japanese students at an Australian university. Journal of Intercultural Studies, 24, 91-114.

Kugele, K. (2006). Junge Global Nomads und ihre Freundschaften. Auswirkungen des Aufwachsens in mehreren Kulturen auf Erleben und Verhalten in Freundschaftsbeziehungen. Gruppendynamik und Organisationsberatung, 37, 155-172.

Levin, S., Laar, C. van, \& Sidanius, J. (2003). The effects of ingroup and outgroup friendship on ethnic attitudes in college: A longitudinal study. Group Processes and Intergroup Relations, 6, 76-92.

Tsai, J. H. C. (2006). Xenophobia, ethnic community, and immigrant youths' friendship network formation. Adolescence, 41, 285-298.

Ward, C., Bochner, S., \& Furnham, A. (2001). The Psychology of Culture Shock. London: Routledge.

Ying, Y. W. (2002). Formation of cross-cultural relationships of Taiwanese international students in the United States. Journal of Community Psychology, 30, 45-55.

Zenteno, R. M. (2000). Redes migratorias: ¿Acceso y oportunidades para los migrantes? Em R. Tuirán (Org.). Migración México-Estados Unidos: Opciones de Política (pp. 229-245). Cidade do México: Consejo Nacional de Población. 